\title{
The Three Dimensions of Species Diversity
}

\author{
Minsheng You $^{*}, 1$, Liette Vasseur ${ }^{2}$, Jacques Régnière $^{3}$ and Yunkai Zheng ${ }^{1}$ \\ ${ }^{1}$ Institute of Applied Ecology, Fujian Agriculture and Forestry University, Fuzhou 350002, PR China \\ ${ }^{2}$ Brock University, 500 Glenridge Ave, St Catharines, ON L2S 3A1, Canada \\ ${ }^{3}$ Natural Resources Canada, Canadian Forest Service, Laurentian Forestry Centre, Quebec, QC G1V 4C7, Canada
}

\begin{abstract}
The concept of biodiversity can be simply defined as the sum of all biotic variation from the level of genes to ecosystems. Biodiversity at the species level, frequently called "species diversity", is a core concept of ecological community and conservation research. To date, however, no single number can fully capture such a concept without loss of information, although many attempts have been made to quantitatively express species diversity. Three aspects of species diversity have received considerable attention in the literature: species richness, evenness and abundance. Current diversity indices often emphasize evenness at the expense of richness or abundance. In this paper, we propose to express species diversity of communities as their position in a three-dimensional volume along the axes of richness, abundance, and evenness. With hypothetical as well as actual examples from our own studies, we discuss the usefulness of this threedimensional approach. We believe that expressing species diversity as a volume is biologically intuitive, easy to interpret numerically and ecologically, and very useful in the assessment and management of biodiversity at the species level.
\end{abstract}

Keywords: assessment, biodiversity, community, evenness, species abundance, species diversity.

\section{INTRODUCTION}

Biological diversity (or biodiversity) has fascinated ecologists for centuries. While in some regions, such as coastal Antarctica, only a few species of plants and animals may be living in a community, hundreds or thousands of species can be found in other habitats, such as in the tropics [1]. Although there have been many different interpretations of diversity [2, 3], the concept of biodiversity is considered to be the integration of biological variability across all scales, from genetic level, through species and ecosystems, to the landscapes that they form, or are part of, and the ecological processes that support them $[4,5]$. The best approach to conserving biodiversity, or minimizing species loss, is therefore to maintain the integrity of ecosystem functions, and to focus on the kinds of biodiversity that are significant to ecosystem functioning and health for continuous provision of particular services and stable resistance to environmental stress such as biological invasions [5, 6]. This is the main reason for the development of approaches to evaluating biodiversity and ecological integrity.

Species are the fundamental units of biological organization, and any small changes in the species diversity may alter to some extent ecosystem functions and services. Species diversity is a fundamentally multidimensional concept that includes species richness, abundance and evenness $[4,7,8]$. Many authors have proposed quantitative expressions or indices of species diversity [7-11], most of

*Address correspondence to these authors at the Institute of Applied Ecology, Fujian Agriculture and Forestry University, Fuzhou 350002, PR China; Tel: (591) 8378-9396; Fax: (591) 8376-8251;

E-mail: msyou@fjau.edu.cn which integrate species richness with the distribution of individuals between the species (evenness) [12,13]. While these indices are commonly used $[1,14]$, confusion about their values has often resulted in misleading interpretation and debate $[13,15]$. No single approach has so far been applicable in all communities or ecosystems [16-18].

In this paper, we discuss the major challenges and limitations regarding the most used measures of species diversity. We then explore the potential representation of biodiversity as a volume in which species richness, species abundance, and species evenness are coordinates. To illustrate the usefulness of this approach, we re-analyze data from a study on arthropod communities in rice fields that compare the diversity patterns of parasitoids and spiders in the assessment of management practices [19].

\section{THE USE OF SPECIES DIVERSITY INDICES}

Categories of species diversity indices have been developed over the past century. The simplest diversity index is species richness which represents the number of species in a community, habitat or in a given sample (area or volume). In addition to the total number of species, richness indices can also include the total number of individuals of all the species in the same habitat, such as Margalef's index [20]. These indices are of limited usefulness as they do not reflect abundance patterns. Species abundance can help characterize the composition and structure of a community. Hill's index has been used for comparison of communities or samples in a given ecosystem (e.g. [21]). Spellerberg proposed to measure abundance as percentage cover in plant communities [22]. Because species abundance is often lognormally distributed [3, 23-26], we think that average log abundance can be a useful expression: 
$\bar{n}=\frac{1}{S} \sum_{i=1}^{s} \log _{10} N_{i}$

where $S$ is species richness and $N_{i}$ the number of individuals of each species. The distribution patterns of individuals among species can be expressed through "evenness" indices that describe the relative abundance or degree of dominance between species $[8,12,27]$. Simpson's $D$ and ShannonWiener's $H^{\prime}$ are the most commonly used indices to define species diversity in ecological and conservation studies [8, 27]. These indices, however, may produce higher values of species diversity with lower species richness and/or abundance, leading to erroneous interpretations and conclusions because they underemphasize species richness, overemphasize evenness, and lose crucial information on species abundance $[10,28]$. For example, consider the six hypothetical communities in Table $\mathbf{1}$, each with five species (same richness) but varying in their abundance. Communities A, B and $\mathrm{C}$ are of equal species evenness (all species have the same relative abundance, thus $E=1$ ). Communities D, E and F vary in absolute species abundance and have unequal relative species abundances, so that evenness is lower but equal among them $(E=0.926)$. The value of $D$ in these communities declines as the absolute abundance of individuals increases among communities with the same richness and evenness (Fig. 1a). It seems irrational for a community with 5 species and 5 individuals per species to have the same $\left(H^{\prime}, E\right)$ or lower $(D)$ diversity than a community with 5 species and 50 individuals per species.

In practice, numbers of species and individuals per species often vary over time within and between growing seasons. This variability can have a considerable impact on the structure of communities. Species diversity is often assessed from series of samples taken over time. An example of this procedure, and of the diversity index estimates associated with such data, is given in Table $\mathbf{2}$. Here, 8 individuals from two species were collected in March, and 58 individuals from three species were collected in April.
Yet the values of both $D$ and $H^{\prime}$ were higher in March than in April (Fig. 1c). Similar results were obtained from samples collected in May and June. Such counterintuitive outcomes, where fewer species lead to higher diversity index values, make little biological sense at least in terms of biological variation and possibly in genetic resources as well as ecological functions, and can have severe consequences in conservation management or ecological monitoring [29-31].

\section{ANOTHER VIEW OF SPECIES DIVERSITY MEASUREMENT}

Taxonomically and numerically speaking, the total sum of biotic variation in a community comes from three main sources: variation in the number of species or species richness, variation in species abundance, and variation in species evenness or species dominance. This information should constitute the basis upon which to express the diversity patterns of a community, habitat or sample at a given time. There are two ways to represent such attributes: as a position in a three dimensional coordinate space (a volume) or as an index.

The advantage of retaining the three main attributes of species diversity is that they fully characterize the vast majority of observed Species Abundance Distributions [32]. Single-valued diversity indices, on the other hand, do not map to unique combinations of these characteristics and thus cannot be disaggregated into their original components. We propose that the data collected on species diversity be described by three distinct numerical attributes: species richness $S$, absolute abundance $\bar{n}$ (equation (1)), and evenness $E$, which can be viewed as three orthogonal coordinates describing the position of a community or sample in a diversity volume (Figs. $\mathbf{1 b}$ and $\mathbf{d}$ ).

The position of a community in this species-diversity volume is more numerically consistent and ecologically intuitive than uni-dimensional indices. We have shown through the previous examples that diversity can be difficult

Table 1. Measurement of Species Diversity of Six Hypothetical Communities

\begin{tabular}{|c|c|c|c|c|c|c|}
\hline & $\mathbf{A}$ & B & C & D & $\mathbf{E}$ & $\mathbf{F}$ \\
\hline Species 3 & 1 & 5 & 50 & 3 & 15 & 30 \\
\hline Species 4 & 1 & 5 & 50 & 4 & 20 & 40 \\
\hline Total species $S$ & 5 & 5 & 5 & 5 & 5 & 5 \\
\hline Total individuals $N$ & 5 & 25 & 250 & 15 & 75 & 150 \\
\hline Abundance $\bar{n}$ & 0 & 0.699 & 1.699 & 0.416 & 1.115 & 1.416 \\
\hline Simpson's $D$ & 1 & 0.833 & 0.803 & 0.810 & 0.766 & 0.761 \\
\hline
\end{tabular}


Table 2. Measurement of Species Diversity Based on Sampled Population Dynamics of Homoptera Herbivores in an Early Rice Field in Fuzhou, Southeast China, 2003

\begin{tabular}{|c|c|c|c|c|c|c|}
\hline & $\begin{array}{c}\text { a } \\
\text { March } 5\end{array}$ & $\begin{array}{c}\text { b } \\
\text { April } 5\end{array}$ & $\begin{array}{c}\text { c } \\
\text { May } 5\end{array}$ & $\begin{array}{c}\text { d } \\
\text { June } 5\end{array}$ & $\begin{array}{c}\text { e } \\
\text { July } 5\end{array}$ & Total \\
\hline Individuals, Sp. 1 & 0 & 5 & 8 & 20 & 5 & 38 \\
\hline Individuals, Sp. 2 & 4 & 45 & 28 & 26 & 40 & 143 \\
\hline Individuals, Sp. 3 & 0 & 0 & 80 & 35 & 20 & 135 \\
\hline Individuals, Sp. 5 & 0 & 0 & 20 & 0 & 0 & 20 \\
\hline Total species $S$ & 2 & 3 & 5 & 4 & 3 & 5 \\
\hline Total individuals $N$ & 8 & 58 & 141 & 106 & 65 & 378 \\
\hline Abundance $\bar{n}$ & 0.062 & 1.085 & 1.251 & 1.415 & 1.201 & 1.758 \\
\hline Pielou's $E$ & 1 & 0.620 & 0.746 & 0.985 & 0.782 & 0.849 \\
\hline
\end{tabular}

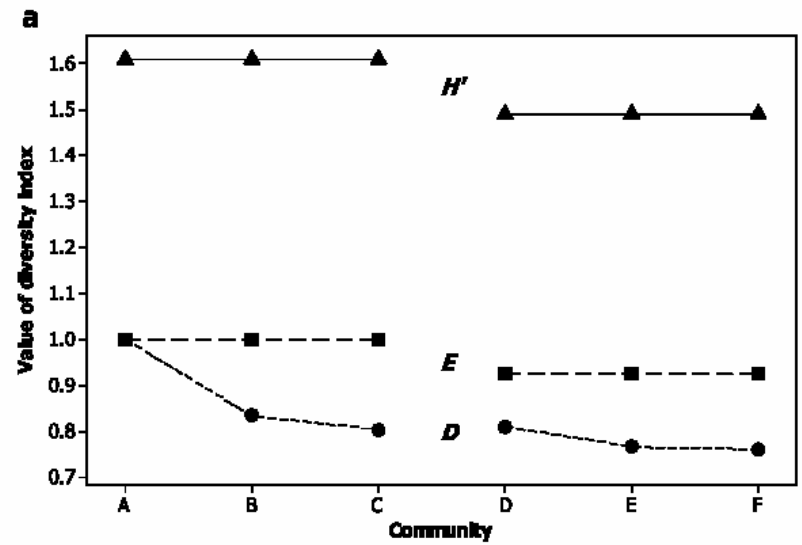

b
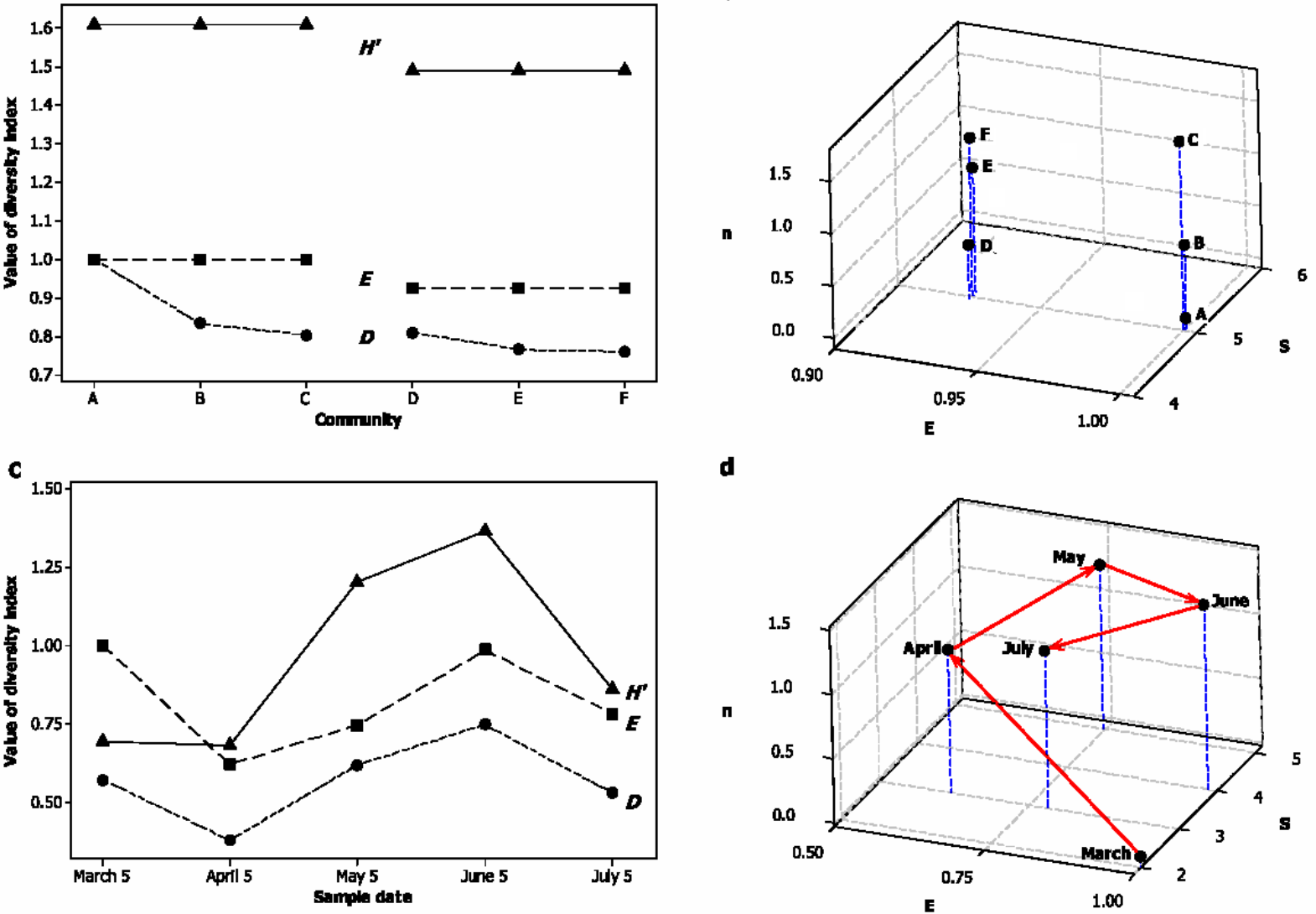

d

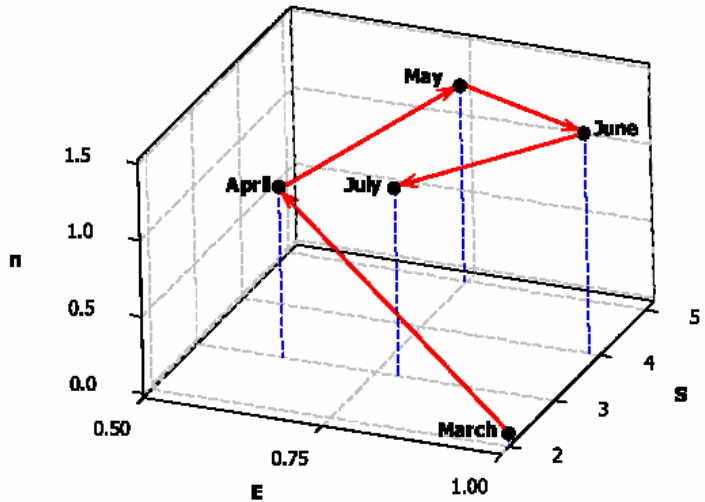

Fig. (1). Patterns of variation of species diversity indices $D(\circ), H^{\prime}(\triangle)$ and $E(\square)$ and 3-D expression of species diversity patterns (a and $\left.\mathbf{b}\right)$ for the six hypothetical communities described in Table $\mathbf{1}$, and (c and $\mathbf{d}$ ) for the five samples from a single community described in Table $\mathbf{2}$.

to interpret in terms of $H^{\prime}, E$ and $D$. (Figs. 1a and c). Retention of richness, abundance and evenness as separate coordinates in a diversity volume (Figs. 1b and d) more fully describes the structure of a community or sample and allows easier assessment, comparison and management of different communities. For example, community A in Table $\mathbf{1}$ or Fig. (1b) is an evenly-distributed and low-abundance community. Its position in the diversity volume $(S=5, E=1$, and $\bar{n}=0)$ 
indicates the necessity of increasing species abundance to reduce the risk of losing those rare species. Similarly, the temporal variation in the diversity of the community described in Table $\mathbf{2}$ is far better represented in Fig. (1d) than it was using the diversity indices in Fig. (1c). The large increase in species abundance in spring (between March and April), is accompanied by a small increase in richness and a decrease in evenness, illustrating the large contribution of Species 2 to overall abundance. Between April and May, several other species also increase in abundance and the evenness increases. This situation remains much the same in June. In July, many species decrease in abundance, but not Species 2, and the community's diversity returns to a state closer to that observed in April.

\section{A CASE STUDY: PREDATORY ARTHROPOD COM- MUNITIES IN RICE FIELDS}

\section{Methods}

As a case study, we use data from a study that reported the changes over time in the community of predatory arthropods (parasitoids and spiders) in rice fields of the Wuyi Mountains, Fujian province, Southeast China [19]. These two groups of natural enemies may be used as biological agents to suppress herbivorous arthropods in rice fields. Briefly, the experimental design consisted of four fields planted with cross-bred rice variety IIYOU125 but each receiving a different treatment: 1) in field A only variety IIYOU125 was planted, with no other treatment; 2) in field B, the rice variety IIYOU125 was intercropped with an indigenous rice variety; 3 ) in field $C$, the variety IIYOU125 was intercropped with a glutinous rice; and 4) in field D, the variety IIYOU125 was sprayed with insecticides. The rice was transplanted from a plant nursery to the fields on June 23 2006, and community surveys (including species richness and abundance) were conducted every 10 days thereafter. The arthropods were sampled from the four fields on seven different dates during the rice growing season, but only data from June 30, July 30 and August 29, which represent seeding, booting and maturing stages of rice respectively, are used here. Field D was used as a seeding nursery prior to the experiment. Pesticides had been applied to the field during that period. New insecticide applications were made on July 3 and 31 to control insect pests in the tillering and booting stages of the rice crop.

In addition to the three-dimensional graphical presentation of the resulting diversity data, a multivariate analysis of variance (MANOVA) was used to test the simultaneous effects of sample date and pesticide treatment on the number of species $(S)$, average abundance $(\bar{n})$ and evenness $(E)$. Ideally, the experimental design should have included field-level replication. However, to illustrate the use of multivariate statistics with this example, fields A, B and $\mathrm{C}$ were considered as replicates receiving no pesticide application, and only the effects of pesticide application and time were tested.

\section{Results}

The various diversity measures obtained for parasitoid and spider communities in the four rice fields and three sample dates are given in Table 3. Among parasitoids, an effect of sample date was apparent in the classical diversity indices ( $H^{\prime}, D$ and $E$ ) from the four rice fields (Fig. 2a). These three indices show the same pattern of decreased diversity in the July samples, and suggest no clear effect of either rice variety mix or pesticide application. The 3D representations (Fig. 2b), on the other hand, show three clear patterns, well supported by the MANOVA results. First, the sample points are clustered by date (Wilk's $\mathrm{F}_{6,8}=56.5, \mathrm{P}<$ $0.001)$. June samples (black symbols) all have low species richness $\left(S_{06}=7.8 \pm 0.9, \mathrm{SEM}\right)$, and medium evenness $\left(E_{06}=\right.$ $0.72 \pm 0.04)$. July samples (green symbols) have high species richness $\left(S_{07}=27.0 \pm 0.9\right)$ but low evenness $\left(E_{07}=0.27 \pm\right.$

Table 3. Measurement of Species Diversity of Predatory Arthropods in Rice Fields of Wuyi Mountains, Fujian, Southeast China

\begin{tabular}{|l|c|c|c|c|c|c|c|c|c|c|c|c|c|}
\hline \multirow{2}{*}{ Field } & \multirow{2}{*}{ Date } & \multicolumn{9}{|c|}{ Parasitoids } & \multicolumn{4}{|c|}{ Spiders } \\
\cline { 3 - 14 } & & $S$ & $\boldsymbol{N}$ & $\bar{n}$ & $\boldsymbol{D}$ & $\boldsymbol{H}^{\prime}$ & $\boldsymbol{E}$ & $\boldsymbol{S}$ & $\boldsymbol{N}$ & $\bar{n}$ & $\boldsymbol{D}$ & $\boldsymbol{H}^{\prime}$ & $\boldsymbol{E}$ \\
\hline \hline Field A & Jun 30 & 9 & 116 & 0.5314 & 0.5514 & 1.1409 & 0.5192 & 13 & 193 & 0.7577 & 0.7216 & 1.6389 & 0.6595 \\
\hline Field B & Jun 30 & 8 & 100 & 0.7411 & 0.7103 & 1.4534 & 0.6989 & 12 & 207 & 0.8874 & 0.6558 & 1.5927 & 0.6409 \\
\hline Field C & Jun 30 & 12 & 146 & 0.5294 & 0.6046 & 1.3470 & 0.5421 & 16 & 302 & 0.7957 & 0.7010 & 1.7392 & 0.6273 \\
\hline Field D & Jun 30 & 6 & 11 & 0.1667 & 0.8000 & 1.5403 & 0.8597 & 4 & 74 & 0.8389 & 0.2699 & 0.5683 & 0.4099 \\
\hline Field A & Jul 30 & 30 & 620 & 0.4494 & 0.2922 & 0.9080 & 0.2670 & 19 & 1082 & 0.9202 & 0.5487 & 1.2605 & 0.4281 \\
\hline Field B & Jul 30 & 31 & 645 & 0.4104 & 0.2895 & 0.8942 & 0.2604 & 18 & 1017 & 1.1818 & 0.7367 & 1.7796 & 0.6157 \\
\hline Field C & Jul 30 & 29 & 665 & 0.5454 & 0.3863 & 1.1255 & 0.3342 & 20 & 1073 & 0.8508 & 0.6501 & 1.4346 & 0.4789 \\
\hline Field D & Jul 30 & 24 & 320 & 0.2742 & 0.2607 & 0.8049 & 0.2533 & 17 & 943 & 0.8834 & 0.4715 & 1.1402 & 0.4024 \\
\hline Field A & Aug 29 & 28 & 182 & 0.4797 & 0.8816 & 2.5564 & 0.7672 & 26 & 2616 & 1.1411 & 0.8134 & 2.0682 & 0.6348 \\
\hline Field B & Aug 29 & 30 & 219 & 0.5407 & 0.9159 & 2.7516 & 0.8090 & 26 & 1817 & 1.1420 & 0.7423 & 2.0235 & 0.6211 \\
\hline Field C & Aug 29 & 31 & 305 & 0.5955 & 0.8226 & 2.3794 & 0.6929 & 30 & 2479 & 1.0347 & 0.7512 & 1.8818 & 0.5533 \\
\hline Field D & Aug 29 & 21 & 48 & 0.1976 & 0.9096 & 2.6053 & 0.8557 & 14 & 1004 & 0.8469 & 0.2190 & 0.5974 & 0.2264 \\
\hline
\end{tabular}


0.04), meaning that they are dominated by a few abundant species. August samples (red symbols) are similar to the July samples in terms of species richness $\left(S_{08}=25.3 \pm 0.9\right)$ but have much higher evenness $\left(E_{08}=0.81 \pm 0.04\right)$. Second, there is a clear effect of insecticide treatment (Wilk's $\mathrm{F}_{3,4}=$ $35.2, \mathrm{P}=0.002)$. The samples from insecticide-treated field $\mathrm{D}$ are characterized by consistently lower abundances $\left(\bar{n}_{D}=\right.$ $0.21 \pm 0.04)$ than untreated fields $\mathrm{A}, \mathrm{B}$ and $\mathrm{C}\left(\bar{n}_{A B C}=0.55 \pm\right.$ $0.02)$ and species richness is consistently lower in field $\mathrm{D}\left(S_{D}\right.$ $=17.0 \pm 0.9)$ than in the other fields $\left(S_{A B C}=23.1 \pm 0.5\right)$. Third, although average species evenness was higher in the treated field $\left(E_{D}=0.65 \pm 0.04\right)$ than in the other fields $\left(E_{A B C}\right.$ $=0.54 \pm 0.02$ ), this difference was obvious only in June and this led to a nearly significant date $\times$ pesticide interaction (Wilk's $\mathrm{F}_{6,8}=3.3, \mathrm{P}=0.063$ ).

Traditional diversity indices applied to these samples are highly correlated to each other and thus convey much the same information. They express the time trend of species evenness, but completely mask effects of time and insecticide application on species richness and do not account for the pattern of abundance that are both so clear in the 3D representation of these data (Fig. 2b) as well as in their multivariate statistical analysis.

Among the spider samples, an effect of sample date was not clearly apparent among the diversity indices, but a reduced evenness was detected in the June and August samples from insecticide-treated field D (Fig. 2c). Other patterns were not clear. The 3D representation (Fig. 2d) again shows clear patterns of diversity among the spider samples. The sample points are also clustered by date, but not as clearly as those from the parasitoid communities (Fig. 2b), particularly because samples from field $D$ show much lower species richness $\left(S_{D}=11.7 \pm 1.1\right)$ and evenness $\left(E_{D}=\right.$ $0.34 \pm 0.04)$ than samples from the other fields $\left(S_{A B C}=20.0\right.$ $\left.\pm 0.6 ; E_{A B C}=0.58 \pm 0.02\right)$. There is also a clear time trend in abundance from June samples (black symbols; $\bar{n}_{06}=0.82 \pm$ 0.07 ) to July (green symbols; $\bar{n}_{0707}=0.93 \pm 0.07$ ) to August (red symbols; $\bar{n}_{0808}=0.98 \pm 0.07$ ). The MANOVA analysis, contrasting treated field $\mathrm{D}$ and non-treated fields suggests that insecticide treatment had a significant overall effect on the three diversity measures taken collectively (Wilk's $\mathrm{F}_{3,4}=$ $38.6, \mathrm{P}=0.002)$. Sample date also had a significant effect (Wilk's $\mathrm{F}_{6,8}=5.6, \mathrm{P}=0.014$ ). Treatment $\times$ time interaction was marginally significant (Wilk's $\mathrm{F}_{6,8}=3.6, \mathrm{P}=0.049$ ) probably because it is in the August sample that abundance was significantly lower in the treated field than in the others (Fig. 2d). Once again, the traditional diversity indices applied to these samples only express the time trend of species evenness, and completely mask the synergetic effects of time and insecticide application on species richness and abundance. The 3D representation of the data (Fig. 2d) gives a much clearer picture of the ecosystem change over time under various conditions.

\section{DISCUSSION}

Species diversity is one of the most important properties of a biological community. It has been a central theme in community and conservation ecology since its inception [7]. It can however be measured and interpreted in different ways and there is a need to continue to examine these different a

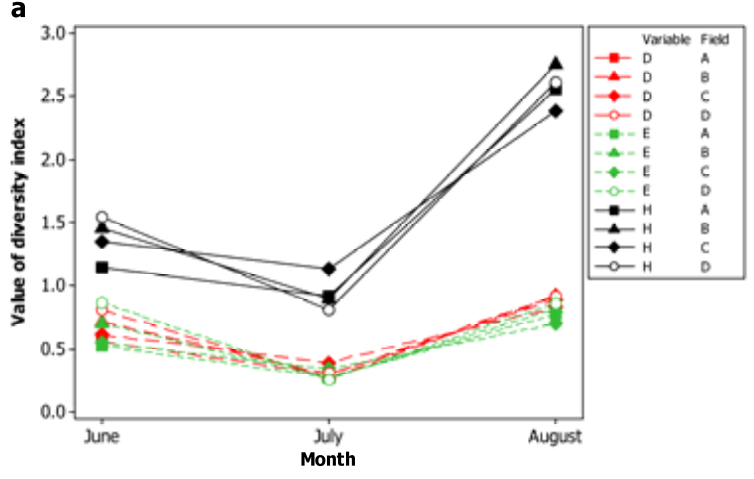

c

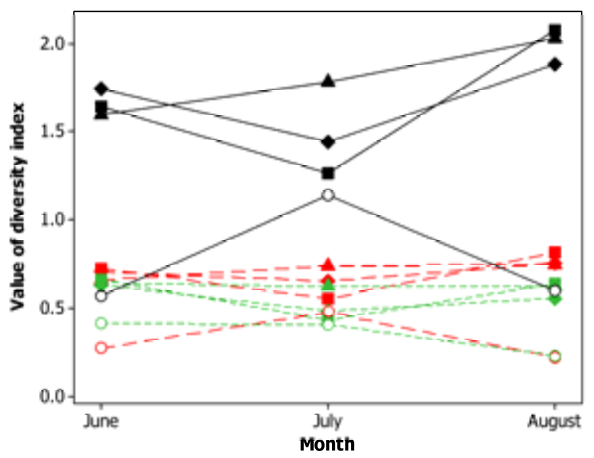

b

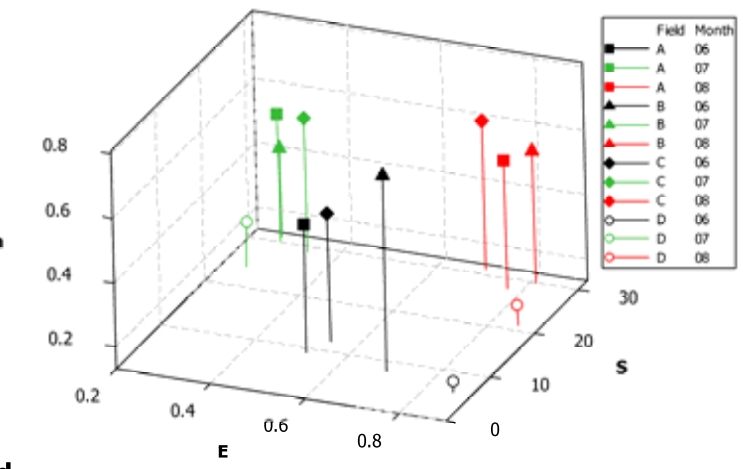

d

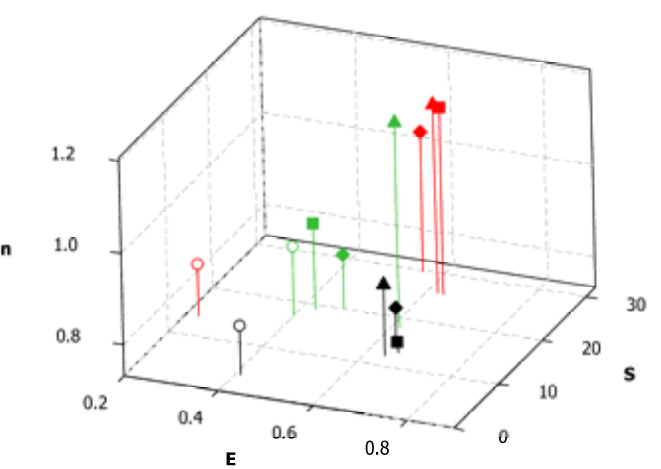

Fig. (2). Patterns of variation of species diversity indices $D(\circ), H^{\prime}(\triangle)$ and $E(\square)$, and 3-D expression of species diversity patterns (a, b) for parasitoids and (c, d) spiders, sampled at different growing stages of rice in four fields $(\mathbf{A}, \mathbf{B}, \mathbf{C}$, and $\mathbf{D})$ (data from Table $\mathbf{3}$ ). 
groups of indices in order to have a more global understanding of their importance in ecology [33]. In this paper, we have discussed the challenges regarding the use of single diversity indices as each of them has limitations. Other studies have also suggested use of other systems to interpret diversity in ecological terms (e.g. [33]). With the need to manage biodiversity and conserve our ecosystems, better inferences about the mechanisms that structure communities could be made if the richness, abundance and evenness of species were more distinctly expressed, while still being taken simultaneously into consideration.

In this paper, we propose to represent the species diversity of communities (or samples) as a set of coordinates in a volume consisting of three orthogonal axes: species richness, abundance and evenness. We argue that positioning communities in this diversity volume fully characterizes their species diversity and is amenable to comparisons of diversity from various locations, groups or times, as it is biologically intuitive, easy to interpret numerically and ecologically, and can be used in the management of species diversity. The species richness and abundance axes have no upper limits and are likely to have ranges that depend on the specific communities or ecosystems being compared or on the sampling schemes being used. Also, equation (1) is formulated to reflect the fact that species abundance in most communities is often logarithmically distributed. But should a specific set of communities or samples not display such a distribution, a scale other than logarithmic could easily be substituted in their comparison. It is important to note that the current approach is quite flexible to various projections and statistical analyses.

The implication of such a new approach is especially important while examining ecological integrity and using the concept of ecosystem health. It has been argued that reduced biodiversity could impact ecological integrity through changes in ecosystem functions and services [31, 34]. However, how does this really happen? How can we assess biodiversity in a way that illustrates the changes in the ecosystem thus reflecting the variation in the level of integrity of the system? Some multimetric or multivariate biological indeces have been used or proposed in the past decades such as indices of biological integrity (IBI; [35, 36] Karr 1981, 1991 or RIVPACS; [37] Wright 1995). There are limitations with several of these indeces and research to further understand the complexity of the ecosystem is needed to continue developing these models [30]. Going back to the previous arguments, the fact that this $3 \mathrm{D}$ representation can help detect where or when the changes are occurring in a specific habitat can become an advantage for ecosystem managers. It combines some of the strong points of both IBI and RIVPACs as one possible combined tool. It can be used while monitoring an ecosystem exposed to disturbance or while assessing which places should be better managed or conserved in a national park for example. The use of the approach can vary as a function of the objectives of the assessment. Further use of this approach will help better define its potential for integration in assessing ecosystem health or ecological integrity.

\section{ACKNOWLEDGEMENTS}

This work was supported by National Key Project of Fundamental Scientific Research (“973" Programs, No.
2006CB100204 and No. 2006CB1020066) in China, and a project of the National Natural Science Foundation of China (No. 30570309) for M.S.Y.

\section{REFERENCES}

[1] Pang XF, You MS. Community ecology of insects. Beijing: Agricultural Press of China 1996.

[2] MacArthur RH, Wilson EO. The theory of island biogeography. Princeton, NJ: Princeton University Press 1967.

[3] Whittaker RH. Communities and ecosystems. New York: Macmillan 1975.

[4] Purvis A, Hector A. Getting the measure of biodiversity. Nature 2000; 405: 212-9.

[5] Walker BH. Biodiversity and ecological redundancy. Conserv Biol 1992; 6: 18-23.

[6] Schulze ED, Mooney HA. Biodiversity and ecosystem function. Berlin: Springer Verlag 1993.

[7] Fisher RA, Corbet AS, Williams CB. The relation between the number of species and the number of individuals in a random sample of an animal population. J Anim Ecol 1943; 12: 42-58.

[8] Simpson EH. Measurement of diversity. Nature 1949;163: 688.

[9] Margalef DR. Information theory in ecology. Gen Syst 1958; 3: 3671

[10] Hurlbert SH. The nonconcept of species diversity: A critique and alternative parameters. Ecology 1971; 52: 577-86.

[11] Smith B, Wilson JB. A consumer's guide to evenness indices. Oikos 1996; 76: 70-82.

[12] Pielou EC. The measurement of diversity in different types of biological collections. J Theor Biol 1966;13: 131-44.

[13] Magurran AE. Ecological diversity and its measurement. Princeton, NJ: Princeton University Press 1988.

[14] You P, Li HH, Wang SX, Xu JS. Diversity of the moth community in the Qilihai wetland, Tianjin. Acta Ecol Sinica 2003; 46: 617-21.

[15] Mouillot D, Lepretre A, Andrei-Ruiz MC, Mouillot F, Viale D. A stochastic model for the spatial distribution of species based on an aggregation-repulsion rule. Popul Ecol 2000; 42: 293-303.

[16] Taylor LR, Kempton RA, Woiwod IP. Diversity statistics and the log-series model. J Anim Ecol 1976; 45: 255-72.

[17] James FC, Rathbun S. Rarefaction, relative abundance, and diversity of avian communities. Auk 1981; 98: 785-800.

[18] Krebs CJ. Ecological methodology. Menlo Park, CA: Addison Wesley Longman 1999.

[19] Liu QQ. Effects of intercropping of varieties and pesticide on arthropod communities in rice fields. Fujian Agriculture and Forestry University: MSc thesis 2007.

[20] Margalef DR. Diversidad de especies en les communideades natural. Pub Inst Biologic Barcelonia 1951; 9: 5-27.

[21] Siebert SF, Belsky JM. Some socioeconomic and environmental aspects of forest use by lowland farmers in Leyte , Philippines and their implications for agricultural development and forest management. Philipp Q Cult Soc 1985; 13: 282-96.

[22] Spelleberg IF, Sawyer WD. Multiple-use, biological diversity and standards. N Z Forest 1995; 39: 21-5.

[23] Preston FW. The commonness and rarity of species. Ecology 1948; 29: 254-83.

[24] Preston FM. The canonical distribution of commonness and rarity: part I. Ecology 1962; 43: 185-215, 410-32.

[25] Preston FM. The canonical distribution of commonness and rarity: part II. Ecology 1962; 43: 410-32.

[26] Sugihara G. Minimal community structure: an explanation of species abundance patterns. Am Nat 1980; 116: 770-87.

[27] Shannon CE, Weaver W. The mathematical theory of communication. Urbana: University of Illinois Press 1949.

[28] Odum EP. Basic ecology. New York: Saunders College Publishing 1983.

[29] You MS. The species richness and diversity of the arthropod communities in rice fields. Entomol Sinica 1997; 4: 238-48.

[30] Zhou XZ, Zhou YD, Bi SD, et al. Seasonal dynamics of arthropod community diversity, evenness and relative stability in peach orchards. Chin J Appl Ecol 2004; 15: 1427-30.

[31] Karr JR. In: Pimentel D, Westra L, Noss RF, Eds. Ecological integrity: Integrating environment, conservation, and health. Washington, DC: Island Press 2000: 209-23.

[32] McGill BJ, Etienne RS, Gray JS, et al. Species abundance distributions: moving beyond single prediction theories to 
integration within an ecological framework. Ecology Letters 2007; 10: 995-1015.

[33] Mendes RS, Evangelista LR, Thomaz SM, Agostinho AA, Gomes LC. A unified index to measure ecological diversity and species rarity. Ecography 2008; 31: 450-56.

[34] Chapin III FS, Zavaleta ES, Eviner VT, et al. Consequences of changing biodiversity. Nature 2000; 405: 234-42.
[35] Karr JR. Assessment of biotic integrity using fish communities. Fisheries 1981; 6: 21-7.

[36] Karr JR. Biological integrity: A long neglected aspect of water resource management. Ecol Appl 1991; 1: 66-84.

[37] Wright JF. Development and use of a system for predicting the macroinvertebrate fauna in flowing waters. Aust J Ecol 1995; 20: 181-97.

(C) You et al.; Licensee Bentham Open.

This is an open access article licensed under the terms of the Creative Commons Attribution Non-Commercial License (http://creativecommons.org/licenses/by-nc/3.0/) which permits unrestricted, non-commercial use, distribution and reproduction in any medium, provided the work is properly cited. 